This is the accepted version of the following article: [Savoji, H. , Hadjizadeh, A. , Maire, M. , Ajji, A. , Wertheimer, M. R. and Lerouge, S. (2014), Electrospun Nanofiber Scaffolds and Plasma Polymerization: A Promising Combination Towards Complete, Stable Endothelial Lining for Vascular Grafts. Macromol. Biosci., 14: 1084-1095.], which has been published in final form at https://doi.org/10.1002/mabi.201300545. This article may be used for non-commercial purposes in accordance with the Wiley Self-Archiving Policy [olabout.wiley.com/WileyCDA/Section/id820227.html].

Public access - Manuscript accepted

Published in final edited form as: Macromol Biosci. 14, 1084-1095, 2014

(doi.org/10.1002/mabi.201300545)

\title{
ELECTROSPUN NANOFIBER SCAFFOLDS AND PLASMA POLYMERIZATION: A PROMISING COMBINATION TOWARDS COMPLETE, STABLE ENDOTHELIAL LINING FOR VASCULAR GRAFTS
}

Houman Savoji, Afra Hadjizadeh, Marion Maire, Abdellah Ajji, Michael R. Wertheimer*, Sophie Lerouge*

Houman Savoji, Prof. Abdellah Ajji, Prof. Michael R. Wertheimer

Institute of Biomedical Engineering, École Polytechnique de Montréal, Montreal, QC, H3C 3A7, Prof. Afra Hadjizadeh, Prof. Abdellah Ajji

Department of Chemical Engineering, École Polytechnique de Montréal, Montreal, QC, H3C 3A7, Houman Savoji, Dr. Marion Maire, Prof. Sophie Lerouge

Laboratory of Endovascular Biomaterials (LBeV), Research Centre, Centre Hospitalier de l’Université de Montréal (CRCHUM), Montreal, QC, Canada

Prof. Michael R. Wertheimer

Department of Engineering Physics, École Polytechnique de Montréal, Montreal, QC, H3C 3A7, Canada, E-mail: michel.wertheimer@polymtl.ca

Prof. Sophie Lerouge 
Department of Mechanical Engineering, École de technologie supérieure, Montreal, QC, H3C 1K3, Canada, E-mail: Sophie.lerouge@etsmtl.ca

\begin{abstract}
In the quest to reduce risk of thrombosis in vascular grafts, it is essential to provide a surface with morphological and mechanical properties close to those of the extracellular matrix beneath the luminal endothelium, and to favor the growth of a confluent, stable monolayer of endothelial cells. This is accomplished here by combining electrospun poly(ethylene terephthalate) (PET) mats with an amine-rich thin plasma-polymerized coating, designated "L-PPE:N". Its deposition does not modify the open, highly porous mats and leads only to small changes in mechanical properties. LPPE:N significantly improves the adhesion and growth of human umbilical vein endothelial cells (HUVEC) and their resistance to flow-induced shear stress. These properties favor the formation of desired confluent HUVEC monolayers on the topmost surface, unlike conventional vascular grafts (ePTFE or woven PET), where cells migrate inside the material. This combination is therefore highly advantageous for the pre-endothelialization of the luminal side of small-diameter vascular prostheses.
\end{abstract}

Keywords: electrospinning, plasma polymerization, mechanical property, surface chemistry, endothelialization. 


\section{Introduction}

Cardiovascular diseases are the leading cause of premature death worldwide, occlusion of blood vessels being a major problem [1]. Autologous grafts from patients' own veins or arteries can provide a solution when angioplasty or stenting are not feasible, but not when treatment is impeded by previous surgery or antecedent vascular disease. In such circumstances, synthetic vascular grafts constitute the only option [2]. Current commercial grafts are made from synthetic polymers, expanded poly(tetrafluoroethylene) (ePTFE) or Dacron ${ }^{\circledR}$ [woven poly(ethylene terephthalate), PET], but they are used clinically only as large-diameter vessels, $>6 \mathrm{~mm}$ [2] since their patency rate is poor as smaller-diameter vessels. This is mainly due to inadequate endothelialization and to mechanical compliance mismatch, which lead to occlusion on account of thrombosis and intimal hyperplasia [3]. Therefore, synthetic scaffolds are required that simulate the mechanical and 3D nano-fibrous morphological properties of the extracellular matrix (ECM) beneath endothelial cells (ECs) [4]. Electrospinning is the ideal technique for producing such micro-/nano-fibrous interconnected network scaffolds of high porosity and large surface area; hence it is an excellent candidate for producing vascular graft scaffolds. Fabrication parameters such as polymer solution and processing conditions can be fine-tuned for particular applications [5].

In recent years, several prototypes of electrospun prosthetic vascular grafts have been reported [6, 7] for tissue engineering purposes, including ones comprising biodegradable polymers, with variable degradation rates, ranging from weeks to years [8-12]. However, their mechanical properties are still not ideal. Moreover, biodegradable scaffolds face some important challenges such as the difficulty to predict and match the degradation rate with vascular tissue growth, and possible cytotoxic degradation products $[13,14]$. In addition, the stability of the endothelium may be impaired on a biodegradable scaffold. Therefore, there exists a need for permanent scaffolds with appropriate physical and biological properties. Electrospun PET appears to be an excellent candidate for small-diameter grafts in regards to mechanical properties, stability, biocompatibility and low cost, but foremost due to the fact that PET vascular grafts have already been FDAapproved and clinically used for a few decades $[15,16]$. Several researchers, including some of us [15, 17-20], recently reported studies of electrospun PET mats with controllable characteristics such as fiber diameters, -orientations and mechanical properties, achieved by varying process 
parameters. However, literature data suggest that achieving good coverage of ECs on such PET scaffolds may be problematic [2]. The reason is the polymer's surface inertness: EC adhesion, growth and resistance to flow-induced shear stress has proven to be limited on PET [17, 21]. This might be overcome by a suitable treatment to increase surface roughness, surface energy, or by grafting bioactive molecules. Candidates for these include dry processes such as irradiation by $\gamma$ rays [22], electron beams [23], lasers [24], ultraviolet photons (UV) [25], and plasma treatment [26], but also wet-chemical treatments with $\mathrm{NaOH}$ [27], hydrogen peroxide $\left(\mathrm{H}_{2} \mathrm{O}_{2}\right)$ [28], or graft polymerization [29]. Wet chemistry is the one most frequently encountered in the literature [3032]; for example, $\mathrm{NaOH}$ was shown to increase surface roughness, hence cell adhesion and proliferation [33]. However, wet-chemical treatments also tend to entrain problems of toxicity and environmental impact [34].

A particularly powerful alternative technique, developed among others by members of this team [35], is the deposition of a plasma-polymerized (PP) coating containing suitable functional groups; examples are primary amines $\left(-\mathrm{NH}_{2}\right)$, or carboxylic groups, known to promote cell adhesion and/or to enable immobilization of biomolecules $[35,36]$. Thanks to the high density and stability of functional groups they can incorporate, PP coatings are more effective than mere plasmainduced grafting of surface-near groups [36]. Oxygen-containing PP coatings on fibrous PCL substrates were reported to be suitable for in vitro muscle tissue development, especially for cellular alignment and myotube formation [37]. Numerous articles have also demonstrated the particular effectiveness of nitrogen-, particularly of amine-containing PP coatings [36-38]. For example, N-rich plasma-polymerized ethylene (L-PPE:N) coatings deposited on PET and PTFE films showed that EC adhesion rate, spreading, focal adhesion, and resistance to flow-induced shear were greatly improved, compared with bare and gelatin-coated PET and PTFE [39]. In other words, L-PPE:N appears to be a particularly promising candidate for the endothelialization of vascular grafts [39].

Therefore, the objective of this study has been to combine optimized nitrogen-rich L-PPE:N coatings with electrospun random nano-fibrous PET scaffolds, and to evaluate these in regards to their composition, morphology, mechanical properties, as well as their ability to favor HUVEC adhesion, growth and resistance to flow-induced shear. 


\section{Experimental Section}

\subsection{Fabrication of PET Nano-Fibre Scaffolds}

\subsubsection{Electrospinning}

PET scaffolds (ePET) were fabricated by electrospinning; since the details have been described earlier [15], we repeat only the essential aspects here. Briefly, $9 \% \mathrm{wt} / \mathrm{vol}$ polymer solution was prepared by dissolving PET pellets (DuPont selar PT 7086, intrinsic viscosity of 1) in 1:1 mixture of analytical grade dichloromethane $\left(\mathrm{CH}_{2} \mathrm{Cl}_{2}\right)$ / trifluoro-acetic acid (TFA) (both from Sigma Aldrich), and gently stirring for $24 \mathrm{~h}$. Two (2) $\mathrm{ml}$ of polymer solution was electrospun at a rate of $0.5 \mathrm{ml} / \mathrm{h}$ for $4 \mathrm{hrs}$ with the aid of a syringe pump, in an enclosure with controlled ambient humidity ( $R H: 8-25 \%)$ and temperature $\left(20-25^{\circ} \mathrm{C}\right.$ ). The power supply provided a constant voltage of $15-17$ $\mathrm{kV}$ between the tip of the grounded spinneret needle (size $22 \mathrm{G}$ ) and the rotating collector. The latter, a drum rotating at $1.6 \mathrm{~m} / \mathrm{s}$ (the diameter, $20 \mathrm{~cm}$, and speed differed from those in ref. [15]), was placed at a distance of $15 \mathrm{~cm}$ from the needle tip. The actual nano-fibre mat was collected on an aluminum foil wrapped around the metal drum. Electrospun mats were first dried in ambient air for ca. 3 days, then cut into pieces and carefully peeled from the aluminum foil for subsequent experiments. The pieces of scaffolds were stored in a desiccator until further use.

\subsubsection{Plasma-Polymerization}

Here, too, we merely present the essentials, because details have been described earlier [38, 40]. L-PPE:N coatings were deposited on the surface of nano-fibre mats in a low-pressure ("L") capacitively coupled radio-frequency (r.f., $13.56 \mathrm{MHz}$ ) glow discharge plasma reactor, using ethylene $\left(\mathrm{C}_{2} \mathrm{H}_{4}\right)$ / ammonia $\left(\mathrm{NH}_{3}\right)$ gas mixtures $\left(\mathrm{C}_{2} \mathrm{H}_{4}\right.$ : $99.5 \%$; $\mathrm{NH}_{3}$ : 99.99\%; Air Liquide Canada Ltd., Montreal, QC). The coatings were deposited at 600 milliTorr (80 $\mathrm{Pa}$ ) pressure in the cylindrical aluminum/steel reactor chamber, flows of the high-purity feed gases being controlled using electronic flow meter/controllers (Vacuum General Inc., San Diego, CA), and admitted into the chamber via a shower-head gas distributor of $10 \mathrm{~cm}$ diameter. The flow rates of $\mathrm{C}_{2} \mathrm{H}_{4}$ "monomer" and of $\mathrm{NH}_{3}, \mathrm{FC}_{2} \mathrm{H}_{4}$ and $\mathrm{FNH}_{3}$, were kept constant at 20 standard cubic centimeters per minute $(\mathrm{sccm})$ and $15 \mathrm{sccm}$, respectively, resulting in a mixture ratio $\mathrm{R}=\mathrm{FNH}_{3} / \mathrm{FC}_{2} \mathrm{H}_{4}=0.75$. The deposition was performed under mild plasma conditions (power, $\mathrm{P}=10 \mathrm{~W}$, negative d.c. bias 
voltage, $\mathrm{V}_{\mathrm{B}}=-40 \mathrm{~V}$ ) for a duration of $15 \mathrm{~min}$. These conditions were previously shown to yield a thin layer, 100 nm, of L-PPE:N on a glass microscope slide [40], with adequate nitrogen and amine concentrations, $[\mathrm{N}]$ and $\left[\mathrm{NH}_{2}\right]$, and minimal solubility in cell-culture media $[40,41]$.

As will be shown later, commercial woven PET samples (“wPET”, Dacron ${ }^{\circledR}$, Medtronic Vascular, Santa Rosa, CA), both bare and L-PPE:N-coated, were also investigated as control materials, mainly in regard to their cell-biological characteristics.

\subsection{Materials Characterization}

\subsubsection{Scanning Electron Microscopy (SEM)}

Selected samples were examined by field-emission scanning electron-microscopy (FE-SEM) using a JEOL model JSM-7600 TFE instrument (JEOL Ltd., Tokyo, Japan) at a voltage of $0.5 \mathrm{kV}$ and a working distance of $4 \mathrm{~mm}$, at different magnifications. Nano-fiber mat surfaces were sputtercoated under vacuum with a thin layer of gold in a dedicated coater for 20 seconds, and were then mounted on a suitable sample holder using double-sided tape. The diameters of 100 randomlyselected fibers (at least two experiments with triplicate samples of both pristine and L-PPE:Ncoated mats) were examined by SEM; Dacron ${ }^{\circledR}$ samples were also examined, both coated and uncoated. Micrographs were analyzed using image analysis software (NIH Image software).

\subsubsection{Mercury Intrusion Porosimetry (MIP)}

Porosity and pore size of nano-fiber mats were determined using an AutoPore IV 9500 instrument (Micromeritics Instrument Corporation, U.S.A.) with a $15-\mathrm{ml}$ penetrometer. The mats were cut into $1.5 \times 3 \mathrm{~cm}^{2}$ rectangles and weighed. A sample was then placed into the cup of the penetrometer, which was closed by tightening the cap. The penetrometer and sample was transferred into the pressure chamber of the porosimeter for measurement to take place. Working pressures were in the range $0.015-220 \mathrm{MPa}$. The determination of porosity is based on the relationship between the applied pressure and the pore diameter into which mercury intrudes, according to the Washburn equation [42]:

$$
D=(-4 \gamma \cos \theta) / P_{L}
$$


where $\mathrm{P}_{\mathrm{L}}$ is the pressure of the liquid, $\mathrm{D}$ is the pore diameter, $\gamma$ is the surface tension of mercury $\left(484 \mathrm{mNm}^{-1}\right)$, and $\theta$ is the contact angle, taken to be $140^{\circ}$ between mercury and the pore wall at ambient temperature [42]. The measured intrusion was corrected for expansion of the penetrometer. The experiment was performed on four nominally identical samples of both bare and L-PPE:N-coated mats.

\subsubsection{Mat Thickness}

The mats' thicknesses were measured using a digital gauge (Film Master, Qualitest, designed for film thickness measurements with better than $10 \mu \mathrm{m}$ resolution). To minimize possible error resulting from compression of the mats during measurements, they were sandwiched between two rigid PET films.

\subsubsection{Tensile Testing (Dry and Wet)}

Tensile properties of the mats were evaluated using a uniaxial tensile testing machine (Instron, ElectroPuls ${ }^{\mathrm{TM}}$ E3000). Samples were prepared by cutting mats into $0.5 \mathrm{~cm} \times 2 \mathrm{~cm}$ strips; a given sample was then inserted into the Instron's jaws, the distance between the upper and the lower jaw being set at $1.5 \mathrm{~cm}$. The tensile test was performed using a $250 \mathrm{~N}$ load cell, at a speed of 10 $\mathrm{mm} / \mathrm{min}$. Young's modulus, yield strength, yield strain, tensile strength and elongation at break were calculated manually using Stress-Strain curves. Samples were tested in the "dry" state (in ambient air) or in the "wet" state. In the latter case, to better mimic physiological conditions in the body, samples were first immersed in phosphate buffered saline (PBS) solution at $37^{\circ} \mathrm{C}$ for $24 \mathrm{~h}$, then cleared from excess liquid using tissue paper and immediately tested as described above. Experiments were repeated three times; at least 12 samples were used in each experiment to test reproducibility.

\subsubsection{Surface-Chemical (XPS) Analyses}

X-Ray photoelectron spectroscopy (XPS) analyses were performed in a VG ESCALAB 3MkII instrument, using non-monochromatic $\mathrm{Mg} \mathrm{K} \alpha$ radiation [38, 40, 41]. The size of the analyzed area was about $1 \mathrm{~mm}^{2}$, and the sampling depth was in the 1-5 nm range on account of the fibers' 
geometries. Spectra were acquired at $0^{\circ}$ emission angles (normal to the mat surface), and charging was corrected by referencing all peaks to the carbon $(\mathrm{C} 1 \mathrm{~s})$ peak at binding energy, $\mathrm{BE}=285.0 \mathrm{eV}$. The X-ray source was operated at $15 \mathrm{kV}, 20 \mathrm{~mA}$. Quantification of data was performed using Avantage v4.12 software (Thermo Electron Corporation) by integrating the area under a specific peak after a Shirley-type background subtraction, and using sensitivity factors from the Wagner table.

For the case of L-PPE:N-coated mats, the near-surface-concentrations of primary amine groups, $\left[\mathrm{NH}_{2}\right]$, were determined using the highly-selective derivatization reaction of 4-(trifluoromethyl) benzaldehyde (TFBA, 98\%, Aldrich) vapor with $\mathrm{NH}_{2}$ groups [43]. By this reaction TFBA is covalently linked via imine bonds, whereby $\left[\mathrm{NH}_{2}\right]$ values could readily be deduced from the fluorine concentrations, $[\mathrm{F}]$, at the surface, determined by XPS, as described in detail in earlier work from these laboratories [38, 40,41]. The reader is referred to those articles for any additional information required. Data acquired by XPS survey spectra of both derivatized and pristine samples were combined to calculate $[\mathrm{N}],\left[\mathrm{NH}_{2}\right]$, and other quantities of interest.

\subsubsection{Chemical Aging after Immersion, and Depth Analysis}

Possible changes in $[\mathrm{N}]$ and $\left[\mathrm{NH}_{2}\right]$ of L-PPE:N-coated mats after water immersion were measured by XPS, as also reported earlier by Ruiz et al. [40]. After immersion in Milli-Q water for 1, 3 and 7 days after deposition of L-PPE:N, XPS measurements were performed on dried samples with and without derivatization, to study possible chemical "ageing" effects, mostly changes in $\left[\mathrm{NH}_{2}\right]$. To assess possible chemical composition gradients across the thickness of a mat, a 2-layer sample of similar thickness was prepared by electrospinning $1 \mathrm{ml}$ of PET solution for $2 \mathrm{~h}$, followed by overnight drying; then, a second layer was electrospun for $2 \mathrm{~h}$ on top of the former, after which the composite sample was coated with L-PPE:N from one side. XPS analyses were performed on the top, bottom and mid-plane locations of this special composite sample by the same procedure as that described above. 


\subsection{Biological Testing}

\subsubsection{Cell Culture and Seeding}

HUVECs (Cell Applications Inc., 200p-05n, lot 2729) were cultured in 1\% gelatin-coated flasks, in complete medium EGM-2 bullet Kit (Lonza, CC-3162), and used at passage \# 3-5. Samples were cut into $1 \times 1 \mathrm{~cm}^{2}$ squares, placed into 24 -well polystyrene culture plates, four samples of each: bare and L-PPE:N-coated electrospun mats; bare and L-PPE:N-coated woven PET (Dacron ${ }^{\circledR}$, Medtronic Vascular, Santa Rosa, CA) and sterilized in $500 \mu \mathrm{L}$ of $70 \%$ ethanol for 5 min, followed by a rinse with sterile water. Samples were dried overnight under a laminar hood. The next day, cloning glass cylinders $(0.8 \mathrm{~cm}$ inner diameter; $1 \mathrm{~cm}$ height $)$ were placed on the samples to prevent their movement after cell seeding, and to prevent cell adhesion outside the sample. HUVECs were detached with $0.05 \%$ trypsin/EDTA (Invitrogen, 25300-054), counted and diluted to obtain a cell suspension of 100,000 cells/ml. $200 \mu \mathrm{L}$ of this solution (20,000 cells) was added to each well. As control, cells were also cultured directly on polystyrene culture plates coated with $1 \%$ gelatin (hereafter "PCP"). After a $4 \mathrm{~h}$ adhesion period, cloning cylinders and medium were removed, wells were rinsed with PBS to remove non-adherent cells, and $500 \mu \mathrm{L}$ of complete medium was added to each well. The plates were incubated for 1, 7, 14 and 21 days, the culture medium being changed every 2 days.

\subsubsection{Cell Adhesion and Growth}

\subsubsection{AlamarBlue Assay}

Cell adhesion and growth was assessed using AlamarBlue reduction assay (Cedarlane, 300251(BT)), during which cell metabolic activity reduces resazurin dye (blue) to resorufin (pink). At days $1,7,14$ and 21 , culture medium was removed and $500 \mu \mathrm{L}$ of complete medium plus $50 \mu \mathrm{L}$ of AlamarBlue were added to each well and incubated for $4 \mathrm{~h}$ at $37{ }^{\circ} \mathrm{C}, 5 \% \mathrm{CO}_{2}$. After $4 \mathrm{~h}, 150$ $\mu \mathrm{L}$ aliquots were pipetted into 96-well plates (Corning) in triplicate, and the plates were examined at excitation/emission wavelengths of $560 / 590 \mathrm{~nm}$ in a fluorescence plate reader (BioTek, Synergy 4). The experiment was repeated three times to assure reproducibility. To confirm these data, the density and homogeneity of cells on the mats were directly observed after staining cells by crystal 
violet solution $(0.075 \% \mathrm{w} / \mathrm{v}$ in a $3 \% \mathrm{v} / \mathrm{v}$ acetic acid solution) for $15 \mathrm{~min}$, rinsed 3 times with Milli$\mathrm{Q}$ water and air-dried prior to capture by microscopy (not shown here).

\subsubsection{Immunofluorescence Analysis ("Live / Dead" Assay)}

To estimate cell survival and distribution on or inside the various mats, HUVEC grown for 1, 7 and 21 days were stained by calcein-AM $(2 \mu \mathrm{M})$ and ethidium homodimer-1 (5.5 $\mu \mathrm{M})$ (Invitrogen) in serum-free medium for $45 \mathrm{~min}$ at $37^{\circ} \mathrm{C}$ in the dark, before rinsing with D-PBS. The polyanionic dye, calcein, produces intense uniform green fluorescence in living cells (excitation/emission, 495 $1515 \mathrm{~nm}$ ). Ethidium homodimer-1 (EthD-1) enters cells with damaged membranes and produces a bright red fluorescence upon binding to nucleic acids in dead cells. The samples were transferred onto microscope slides and green (live) or red (dead) cells were imaged with Olympus FV10MSASW software under a Laser Confocal Scanning Microscope (Olympus multiphoton FV-1000 MER, Olympus, Canada). Both planar and Z-stack images (images of planes at various depths within the sample) were taken.

\subsubsection{Scanning Electron Microscopy (SEM)}

To visualize cell morphology on controls and modified scaffolds, some samples with cells grown for 7 and 21 days were fixed at room temperature for $1 \mathrm{hr}$ with 3\% glutaraldehyde (diluted in PBS), before rinsing twice with PBS. Thereafter, they were dehydrated in successive ethanol solutions of different concentrations (30, 50, 70, 95 and twice 100\%; 10 min each). Samples were air-dried under a hood overnight, then mounted and gold- coated (Coater: Emitech, K550X) for 2 min for SEM (Hitachi, S-3600N).

\subsubsection{Cell Resistance to Laminar Shear Stress}

To study the HUVECs' resistance to shear when on mats, the following procedure was used: Samples from the two types of electrospun mats (L-PPE:N coated and uncoated) were cut (10 mm x $22.5 \mathrm{~mm}$ ), placed in 6-well polystyrene culture plates, sterilized in $2 \mathrm{ml}$ of ethanol $(70 \%$, in MilliQ water) for $5 \mathrm{~min}$, and then left to dry under the hood overnight. Next, perforated press-toseal silicone isolators ( $5 \mathrm{~mm}$ x $20 \mathrm{~mm}$ x $2.5 \mathrm{~mm}$; Cat. S5560, Sigma-Aldrich, Canada) were placed 
on the mats to constrain cell seeding. Mats were then seeded with HUVECs $(250 \mu \mathrm{L}$ in complete medium, passage \# 3-5, $10^{6}$ cells/mat), which were left to adhere during 48 hrs to obtain a confluent monolayer of cells. Following this, the cell-populated mats were subjected to laminar flow-induced shear stress for one hour in a parallel-flow chamber (Glycotech, C 31-001, Gaithersburg MD, USA). This setup consists of a peristaltic pump to produce laminar flow; a coiled heat exchanger to maintain the medium's temperature; and the actual flow chamber, comprising a stack on the gasket ( $5 \mathrm{~mm} \times 20 \mathrm{~mm} \times 0.25 \mathrm{~mm}$ ), assembled as specified by the manufacturer. The pump was run at $6 \mathrm{~mL} \mathrm{~min}^{-1}$, to obtain a shear stress of ca. 15 dynes $\mathrm{cm}^{-2}$ (similar to an actual physiological value $[44,45])$ in the flow chamber, and maintained for $1 \mathrm{hr}$. Since cell detachment generally occurs during the first 30-45 min, the $1 \mathrm{hr}$ duration was felt to suffice in order to assess the cells' adhesion strength $[39,46]$. The numbers of cells retained on the mats after shear stress tests were compared with those on similar surfaces that had not been tested, by measuring the cells' metabolic activity by AlamarBlue assay (Cedarlane, 30025-1(BT)). The morphology and distribution of the cells was also inspected by SEM (Hitachi, S-3600N) after sample preparation, as described above.

\subsection{Statistical Analysis}

All data are expressed as means \pm SD. Statistical analysis was carried out using ANOVA with Bonferroni-Holm's post hoc analysis, or by independent t-test when comparing 2 groups only (pristine vs L-PPE:N-coated). Values of p lower than 0.05 were considered significant for all tests.

\section{Results and Discussion}

\subsection{Physical Properties of Pristine and of L-PPE:N-Coated Mat Samples}

\subsubsection{Scanning Electron Microscopy (SEM)}

Figure 1 shows a SEM micrograph of a typical electrospun (“ePET") mat after L-PPE:N deposition, thin enough not to lead to perceptible differences between bare and plasma-coated samples (bare and coated Dacron ${ }^{\circledR}$ samples are not shown here). The micrograph clearly illustrates the randomly interconnected web structure of the electrospun PET nano-fibers, which display smooth surfaces devoid of "beads" (spherical defects). This confirms favorable processing 
conditions. Nano-fiber diameters could readily be obtained from micrographs like Figure 1, and values were found to be in the range from 200 to $800 \mathrm{~nm}$, see Figure 2. Mean values of $551 \pm 91$ $\mathrm{nm}$ and $567 \pm 111 \mathrm{~nm}$ were found for untreated and plasma-coated mats, respectively, with a mean increase of only $16 \mathrm{~nm}(\mathrm{n}=200, \mathrm{p}=0.2868)$. This is much less than the nominal $\sim 100 \mathrm{~nm}$ deposit thickness expected, based on values measured on flat surfaces. While the large variability in fiber diameters (see Figure 2) may obscure variations due to coating, several other factors explain why electrospun mats have thinner coatings than flat substrates. First, the high porosity of the mat greatly increases the surface area to be coated and, second, fibers deep within the mats are less readily accessible to the plasma's active precursor species.

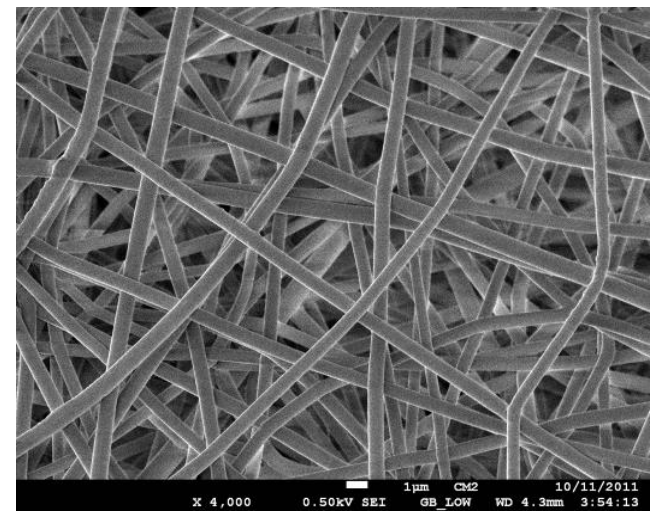

Figure 1 SEM micrograph of a plasma-coated electrospun PET nano-fiber mat; no distinction was possible between pristine (bare) and plasma-coated materials (scale bar: $1 \mu \mathrm{m}$ ). 


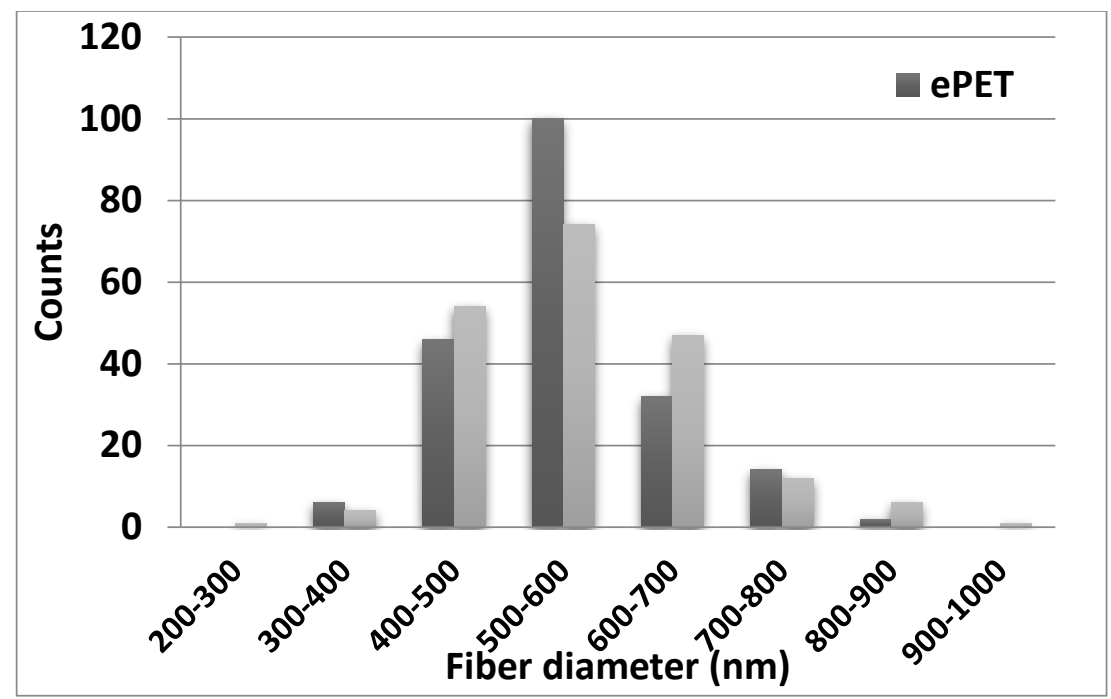

Figure 2 Distributions of fiber diameters, as-prepared (ePET); after deposition of L-PPE:N (ePET-LPPE:N).

The results of mat thickness measurements show significant variation from the center to the edges (50-90 $\mu \mathrm{m})$. Therefore, samples for later experiments, for example tensile tests, SEM, biological tests, and others, were taken exclusively from the central portions.

\subsubsection{Mercury Intrusion Porosimetry (MIP)}

Mercury intrusion porosimetry results are shown in Figure $\mathbf{3}$ and Table 1. Properties such as porosity, pore dimension and volume directly influence successful use of a given scaffold. The overall porosity of the present mats, $87 \%$, is highly desirable for the intended application, vascular grafts, by readily permitting the transport of nutrients, metabolic wastes and gases [46]. Moreover, as seen later in this text, the pore size is low enough to avoid EC intrusion into the scaffold. As expected, the porosity did not change significantly after plasma coating, also in agreement with SEM analysis (Figure 1). On the other hand, the total intrusion volume and average pore diameter (4V/A) tend to be slightly decreased after plasma-coating (Table 1), although the number of samples investigated was too small for statistical analysis. 


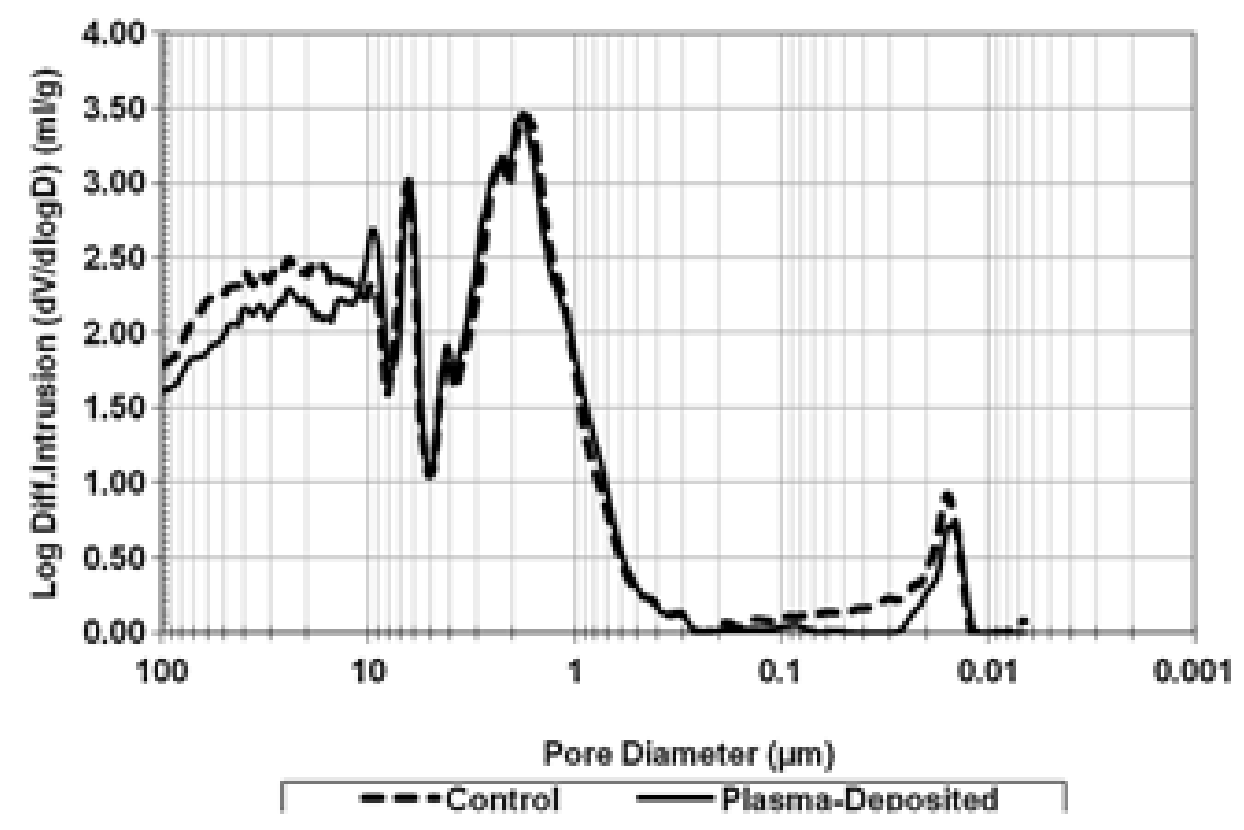

Figure 3 Pore-size distributions of pristine (bare) and L-PPE:N coated electrospun PET nanofiber mats $(n=4)$.

Table 1 Porosity and pore properties of electrospun mats, bare and L-PPE:N-coated ( $n=4)$.

\begin{tabular}{|c|c|c|c|}
\hline Sample & $\begin{array}{c}\text { Intrusion } \\
(\mathbf{m l} / \mathbf{g} \text { sample })\end{array}$ & $\begin{array}{c}\text { Porosity } \\
(\boldsymbol{\%})\end{array}$ & $\begin{array}{c}\text { Average Pore Diameter } \\
(\mathbf{4 V} / \mathbf{A})(\boldsymbol{\mu m})\end{array}$ \\
\hline Bare mat & $5.3 \pm 0.4$ & $87 \pm 1$ & $3.2 \pm 0.5$ \\
\hline Coated mat & $4.7 \pm 0.4$ & $86 \pm 1$ & $2.5 \pm 0.9$ \\
\hline
\end{tabular}

\subsubsection{Mechanical Properties}

The tensile properties of pristine (bare) and plasma-coated mats were measured in the length direction of the $0.5 \mathrm{~cm} \times 2 \mathrm{~cm}$ sample strips. Knowledge of stress-strain behavior of nano-fiber mats facilitates understanding their performance under dynamic stress encountered in use. Tensile properties under dry and wet conditions are summarized in Table 2, while Figure 4 shows a typical stress-strain plot; bare and L-PPE:N-coated mats led to nearly indistinguishable curves. The PET mats were seen to exhibit elastic (linear) behavior up to about $1 \mathrm{MPa}$, followed by further 
deformation and rupture at about $250 \%$ of elongation. In the presence of the L-PPE:N coating, the ultimate tensile stress was found to be slightly increased while maximal strain was reduced (p < 0.05). Young's moduli of the coated mats were also somewhat higher (34 \pm 7 vs $20 \pm 6 \mathrm{Mpa}$; $<<$ 0.05), confirming that coated electrospun mats are slightly stiffer, indicative of an eventual graft's overall mildly reduced compliance. This may be due to the fact that L-PPE:N tends to "glue" nanofibers together, thereby impeding their ready displacement under applied load. No statistical differences were found between dry and wet mats, both bare and coated.

The Young's moduli of ePET mats, bare or L-PPE:N-coated, are still above those of natural arteries (see Table 2) but they can be advantageous in comparison to ePTFE and woven structures of highly oriented PET; furthermore, the characteristics can be adjusted by chemical means [27], or by plasma etching (to be published), if required. Tensile strength is similar to published values for various arteries and veins, indicating that the burst pressure would also be in the same range. Elongation at break was found to be greater than that of arteries in all cases, but not believed to be problematic. However, while uni-axial tensile tests allow one to estimate elastic properties of the fabricated scaffolds, they do not directly provide their compliance (a multi-axial property). Therefore, further tests would be desirable, in particular ones designed to assess compliance and fatigue resistance of tubular multilayered grafts; this is the subject of future work. 
Table 2 Mechanical properties of bare and L-PPE:N-coated electro-spun PET mats under dry and wet conditions (three experiments, at least 12 samples in each experiment). Young's modulus was calculated in the linear portion of the stress-strain curve. Data are presented in comparison with values from the literature.

\begin{tabular}{|l|c|c|c|c|c|}
\hline Sample & $\begin{array}{c}\text { Young's } \\
\text { Modulus } \\
(\mathbf{M P a})\end{array}$ & $\begin{array}{c}\text { Yield } \\
\text { Strength } \\
(\mathrm{MPa})\end{array}$ & $\begin{array}{c}\text { Yield } \\
\text { Strain } \\
(\%)\end{array}$ & $\begin{array}{c}\text { Tensile } \\
\text { Strength } \\
(\mathrm{MPa})\end{array}$ & $\begin{array}{c}\text { Elongation } \\
\text { at } \\
\text { Break (\%) }\end{array}$ \\
\hline ePET (dry) & $20 \pm 6\left(^{*}\right)$ & $0.85 \pm 0.1\left(^{*}\right)$ & $7 \pm 2\left(^{*}\right)$ & $1.7 \pm 0.2\left(^{*}\right)$ & $247 \pm 88\left(^{*}\right)$ \\
\hline ePET- L-PPE:N (dry) & $34 \pm 7\left(^{*}\right)$ & $1.2 \pm 0.2(*)$ & $5 \pm 1.1\left(^{*}\right)$ & $2.1 \pm 0.3(*)$ & $164 \pm 39\left(^{*}\right)$ \\
\hline ePET (wet) & $21 \pm 8$ & $1.0 \pm 0.3$ & $6.2 \pm 2.2$ & $1.9 \pm 0.5$ & $211 \pm 27$ \\
\hline ePET- L-PPE:N (wet) & $28 \pm 9$ & $1.1 \pm 0.3$ & $4 \pm 0.7$ & $1.9 \pm 0.4$ & $139 \pm 23$ \\
\hline Human Saphenous Vein [47] & 15 & - & - & 1 & - \\
\hline Human Femoral Artery [48] & $9-12$ & - & - & $1-2$ & $63-76$ \\
\hline Human Coronary Artery [49] & - & - & - & $1.4-11$ & $55-99$ \\
\hline
\end{tabular}

* Significant difference at the 0.05 level between two mat-types (bare and L-PPE:N-coated)

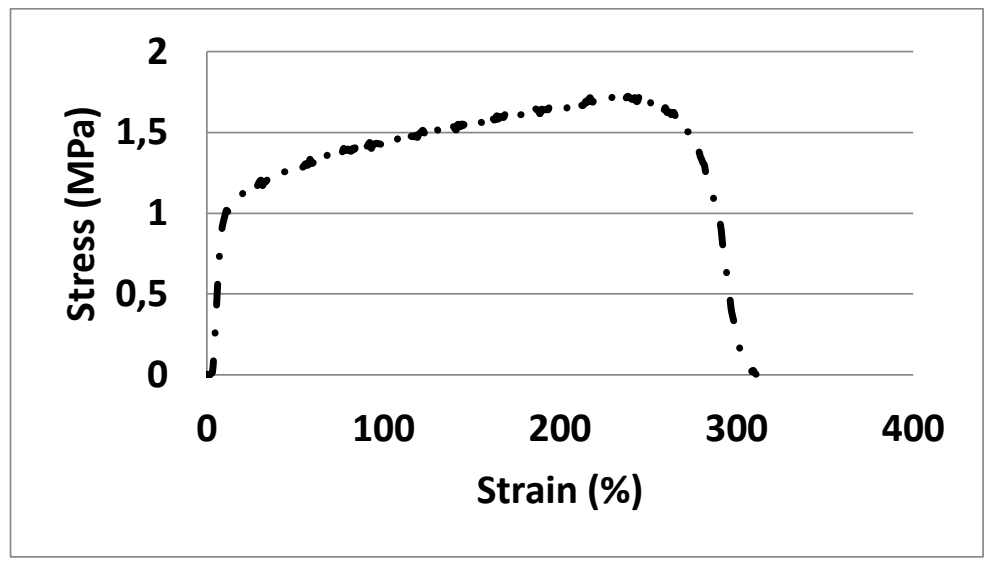

Figure 4 Typical tensile test (stress-strain) results for a nano-fibre mat; curves corresponding to bare and L-PPE:N-coated samples had very similar characteristics. 


\subsection{Chemical Properties of Bare and L-PPE:N-Coated Mat Samples}

\subsubsection{Chemical Composition and Its Depth-Dependence}

Using the special L-PPE:N-coated 2-layer mat sample described earlier, XPS measurements were carried out on top ([a]: $0 \mu \mathrm{m}$ ), in the middle ([b]: $45 \mu \mathrm{m}$ ) and on bottom ([c]: $90 \mu \mathrm{m}$ ) positions, respectively $(\mathrm{n}=3)$. Respective values of $[\mathrm{N}]$ in each of those three locations were as follows: [a]: $13 \%$; [b]: $5 \%$; [c]: $5 \%$. Although [N] is seen to have decreased with increasing depth, it was clearly non-zero in positions $[\mathrm{b}]$ and $[\mathrm{c}]$, several tens of micrometers below the surface of the mat during its exposure to the plasma. This reveals beyond doubt that active species from the plasma penetrated through the mat's porous structure.

\subsubsection{Ageing under Wet Conditions}

Figure 5 shows ageing behavior (surface-chemical changes) of L-PPE:N-coated mats following immersion in Milli-Q water for 1, 3 and 7 days: We first note an appreciable increase in [O], accompanied by a decrease in $[\mathrm{N}]$ during the first 3 days, after which changes became smaller; as expected, $\left[\mathrm{NH}_{2}\right]$ also decreased somewhat during immersion. The latter is due to reactivity of primary amines with oxygen and humidity; amides, ketones and aldehydes are the likely main reaction products, as revealed by earlier research in these laboratories [40, 41]. Despite this small decrease, $\left[\mathrm{NH}_{2}\right]$ remained at a relatively high value (above $4 \%$ ) compared to other functionalization techniques, for example by plasma modification [50, 51]. This is of key importance, because $\left[\mathrm{NH}_{2}\right]$ plays an essential role in promoting cell-adhesion. 


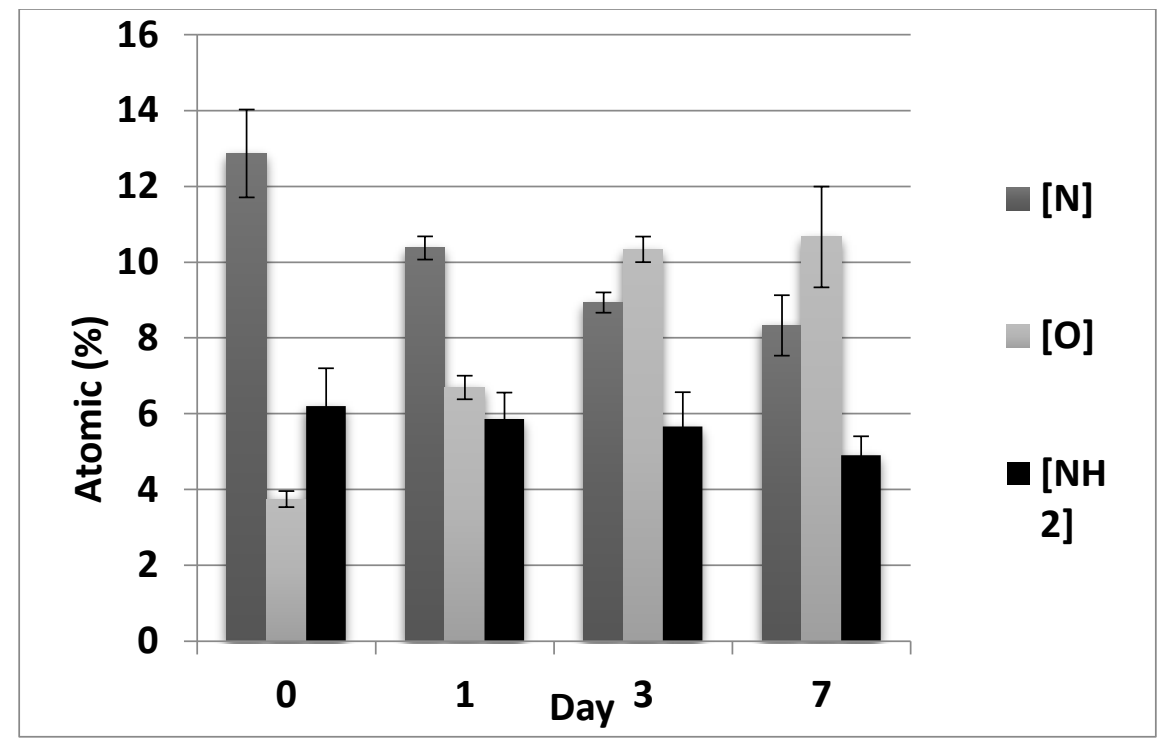

Figure 5 Ageing of L-PPE:N-coated mats after immersion in Milli-Q water for various durations, namely 1,3 , and 7 days (XPS; $n=3$ ).

\subsection{Cell Adhesion, Viability and Proliferation on Bare and L-PPE:N-Coated Mat Substrates}

HUVEC response to the electrospun mat scaffolds (ePET), to woven PET (Dacron ${ }^{\circledR}$, “wPET”), and to PCP (as positive control) was investigated by measuring the ability of cells to adhere and proliferate on the various materials, both bare and L-PPE:N-coated, see Figure 6. Adhesion after 24h (day 1) on the bare mat (ePET) was significantly less than on PCP. ePET-LPPE:N significantly increased adhesion ( $<<0.05)$, to the point of being the same as on PCP. In other words, plasma-coating of the electrospun mat resulted in a much greater population density of adhering cells. This was presumably due the much enhanced surface activity of L-PPE:N resulting from its primary amine groups, also evidenced by previously published research from these and other laboratories [37, 39, 41, 52].

HUVEC growth at days 4, 7, 14 and 21 was also found to be significantly $(\mathrm{p}<0.05)$ higher on the plasma-coated mat than on the bare one (compare data "ePET" and "ePET-LPPE:N"). In actual fact, AlamarBlue reduction induced by cells on a bare mat was observed to even decrease between days 1 and 7, but it then rose on days 14 and 21; Ma et al. [53] reported similar behavior for human coronary artery endothelial cells on electrospun PET nano-fibrous mats with and without gelatin- 
coating. Here, however, L-PPE:N coating enhanced HUVEC density during the entire culture period, days 1 to 21 (see "ePET-LPPE:N"). Adhesion was even higher than on the positive control, gelatin-coated PCP. The higher values obtained with PCP at days 14 and 21 should not be taken into consideration, because in PCP wells cells could migrate during the growth period and cover a larger area, $\sim 1.9 \mathrm{~cm}^{2}$, compared with only $\sim 1 \mathrm{~cm}^{2}$ in the case of ePET mats.

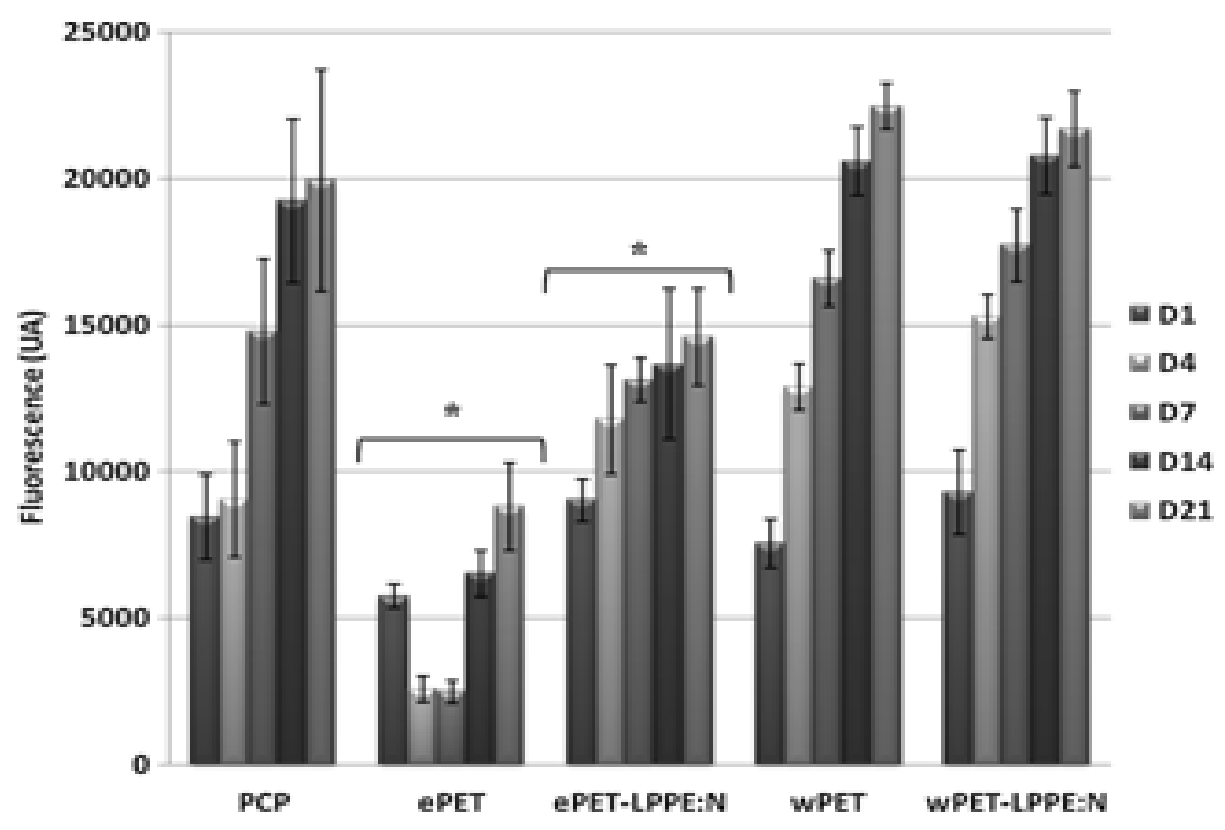

Figure 6 Growth of HUVECs on different bare and L-PPE:N-coated substrate surfaces, after different culture times (PCP: tissue-culture polystyrene; ePET: electrospun mats; wPET: woven Dacron ${ }^{\circledR}$ fabric; LPPE:N: L-PPE:N-coated) ( $\mathrm{n}=9$ for each)

${ }^{*}$ Significant difference between bare and L-PPE:N-coated ePET $(\mathrm{p}<0.05)$

In comparison with ePET, the bare and plasma-coated Dacron ${ }^{\circledR}$ exhibited even higher cell numbers at each time point (except day 1) $(\mathrm{p}<0.05)$. This was not unexpected, because this material's large pores enabled cell migration into those, as observed here by confocal and scanning electron microscopy. In contrast, the smaller $(2.5-3.5 \mu \mathrm{m})$ pores of electrospun mats restrain cells to the topmost surface, an important advantage for forming a confluent monolayer of endothelial cells on the lumen side of a graft. Confocal microscopy images are presented in Figure 7, where the upper portion portrays planar views of cell populations on the different substrates, on days 1, 7 and 21. On each of the surfaces the numbers of dead cells (red) was very small. Both the planar 
(upper) and the Z-stack (lower portion of Figure 7) images confirmed that on Dacron ${ }^{\circledR}$ (wPET), the cells penetrated inside the scaffold, while on ePET, where they remained confined at the surface, fluorescence is seen to have remained concentrated on a surface layer of ca. $10 \mu \mathrm{m}$ thickness. This was also confirmed by SEM images, which show a near-confluent monolayer of endothelial cells on the coated electrospun mat at day 21 (Figure 8): Figure 8(a,b) clearly reveals the flat, spread morphologies of HUVECs after 21 days on the pristine [8(a)] and L-PPE:N-coated [8(b)] electrospun PET mats, respectively. Fewer cells are observed on the bare mat (ePET) than on its coated counterpart, ePET-LPPE:N, in qualitative agreement with earlier-mentioned results by others. [7, 33, 53] Figure 8(c,d) shows that HUVEC penetrated inside the voids of bare (wPET) and coated Dacron ${ }^{\circledR}$ (wPET-LPPE:N), as already pointed out while discussing Figure 7.

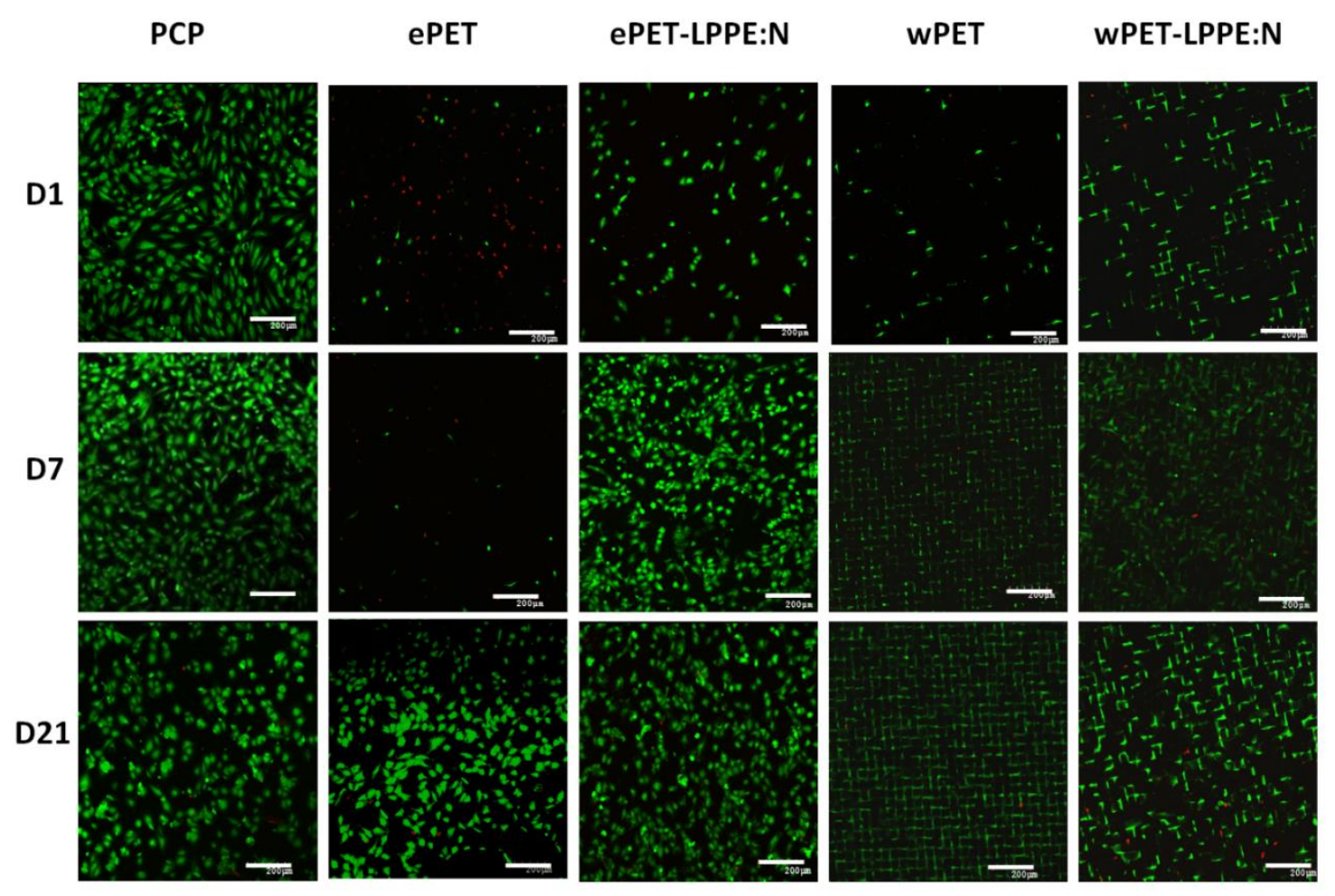



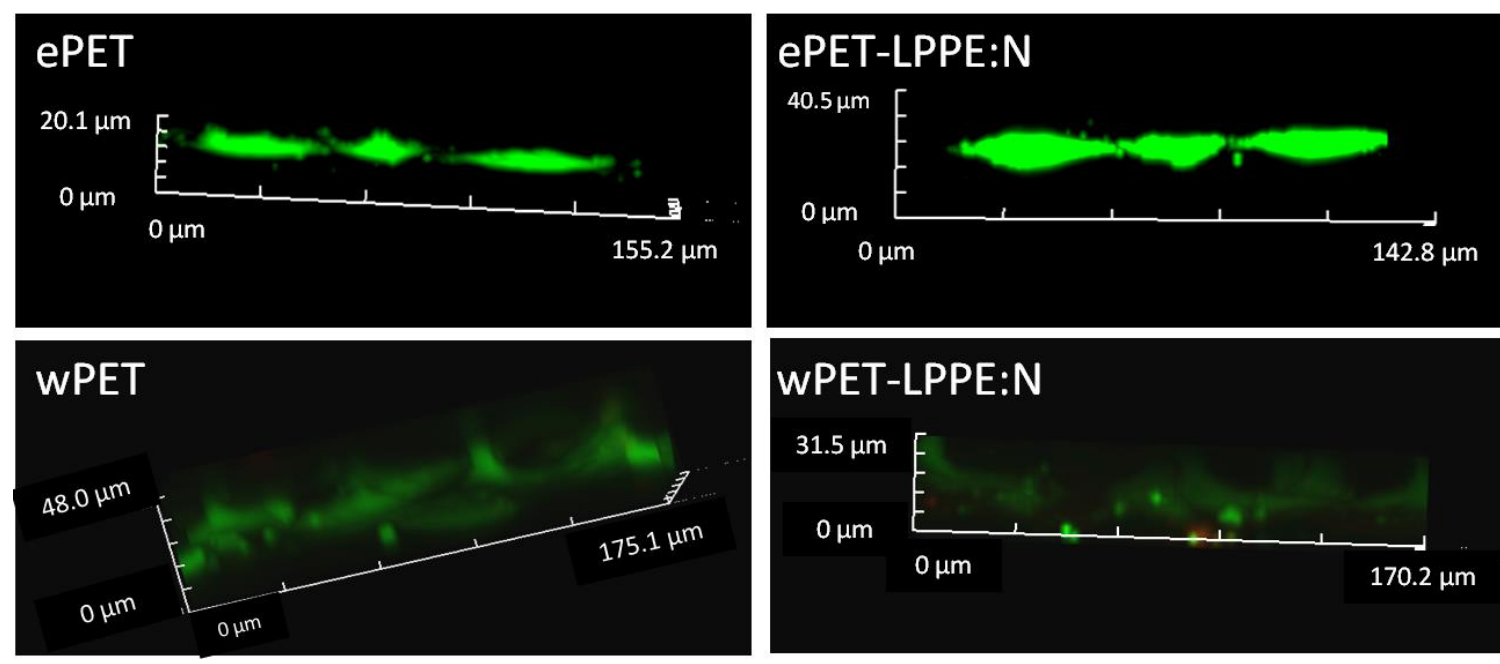

Figure 7 Confocal microscopy images of immunofluorescence-stained HUVECs on the various substrates identified at the top; different rows represent days 1, 7 and 21 of culture (scale bar: $200 \mu \mathrm{m})$. The bottom row shows Z-stack images after 21 days.
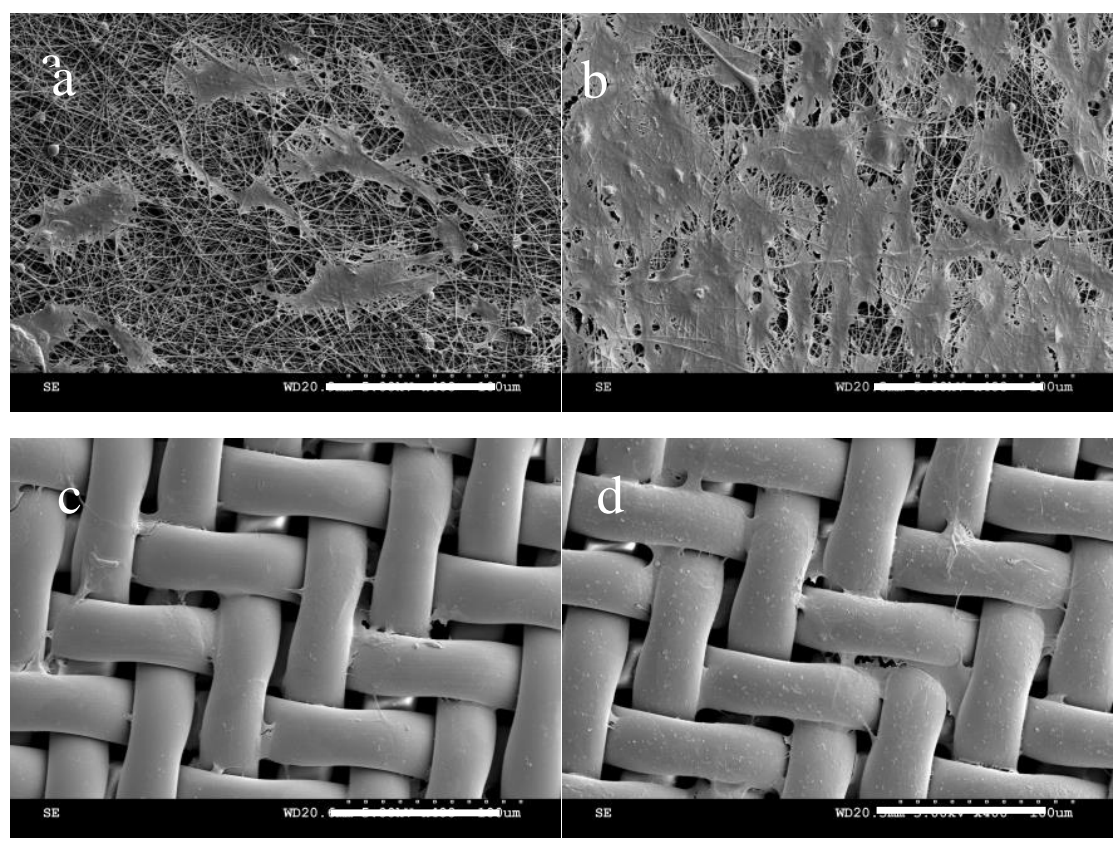

Figure 8 SEM micrographs of electrospun nanofiber mats with HUVECs after 21 days of growth: a) bare mat (ePET); b) mat after L-PPE:N coating; c) bare woven PET (wPET, Dacron $^{\circledR}$ ); d) woven PET after L-PPE:N coating (scale bar: $100 \mu \mathrm{m}$ ) 
Together, these results therefore tend to confirm our hypothesis that electrospun nanofiber scaffolds can provide a structure akin to the base-membrane of natural arteries [7, 49, 54]. However, while cell adhesion, viability and proliferation allow one to estimate the biocompatibility and non-cytotoxicity of the fabricated scaffold, more detailed studies would be desirable to evaluate its efficacy as a graft material.

\subsection{Cell Resistance to Laminar Shear Stress}

HUVEC retention on bare and L-PPE:N-coated ePET mats was investigated using the parallelflow chamber with a typical physiological shear stress value of 15 dynes $\mathrm{cm}^{-2}$, for $1 \mathrm{hr}$. Figure 9 shows AlamarBlue results after $48 \mathrm{hrs}$ of adhesion and growth, subjected or not to shear. Cell retention was found to be promising for L-PPE:N-coated mats, with approximately $70 \pm 4 \%$ and $30 \pm 10 \%$ of the cells remaining on coated and bare mats, respectively ( $p<0.05)$. Once again, in this experiment L-PPE: $\mathrm{N}$ coating was also found to have increased the initial adhesion and $48 \mathrm{hrs}$ growth of cells under static conditions. However, the difference with bare ePET was less marked, probably due to the fact that large numbers of cells were seeded, $10^{6}$ cells per mat. It has been reported [55] that the influence of the substrate on cell adhesion can be reduced when cell density is very high, possibly due to cell-cell interactions that may dominate over those with the substrate. After exposure to shear, cell densities were significantly greater on ePET-LPPE:N than on bare (ePET) samples ( $\mathrm{p}<0.05$ ), as also confirmed by SEM observation (Figure 10). This agrees with earlier-published results from these laboratories $[39,56]$, which showed strong adhesion and retention of endothelial cells on L-PPE:N coated flat substrates. 


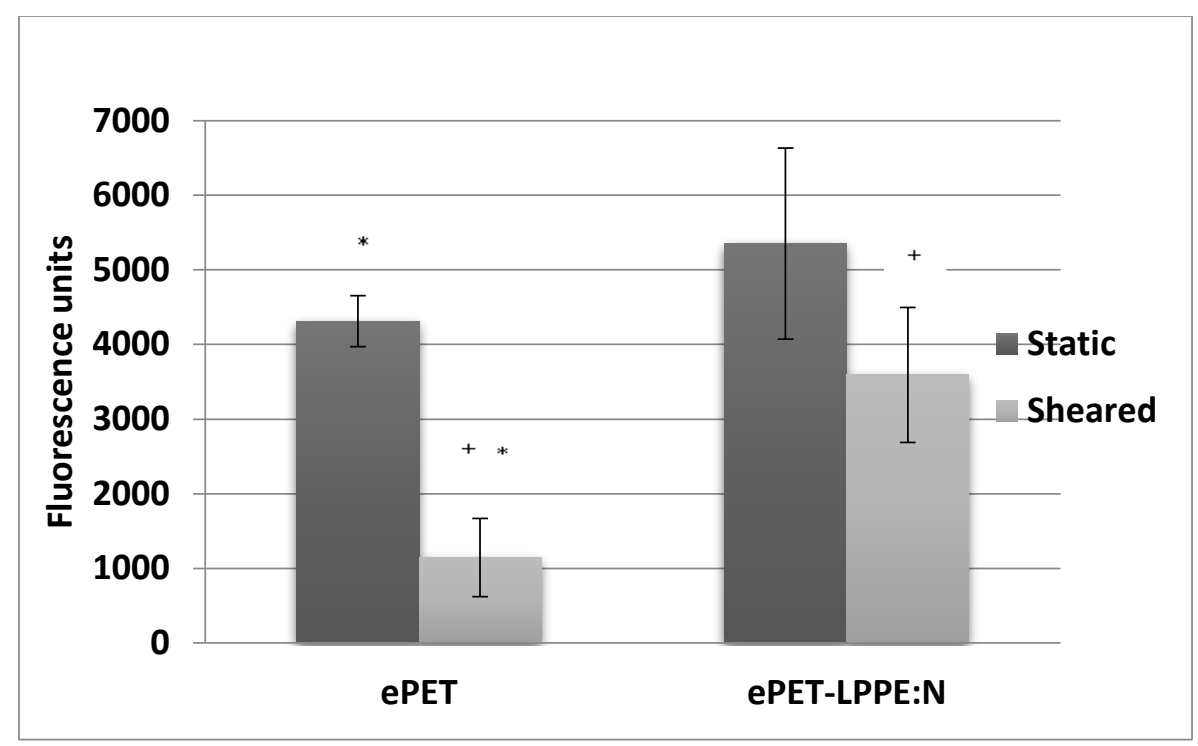

Figure 9 HUVECs' resistance to laminar shear stress (15 dynes $\left./ \mathrm{cm}^{2}, 1 \mathrm{~h}\right)$, evaluated by AlamarBlue assay ( $\mathrm{n}=12$ for each mat). * Significant difference at the 0.05 level between ePET mats under static and shear conditions. + Significant difference at the 0.05 level between bare and L-PPE:N-coated ePET mats under shear condition.
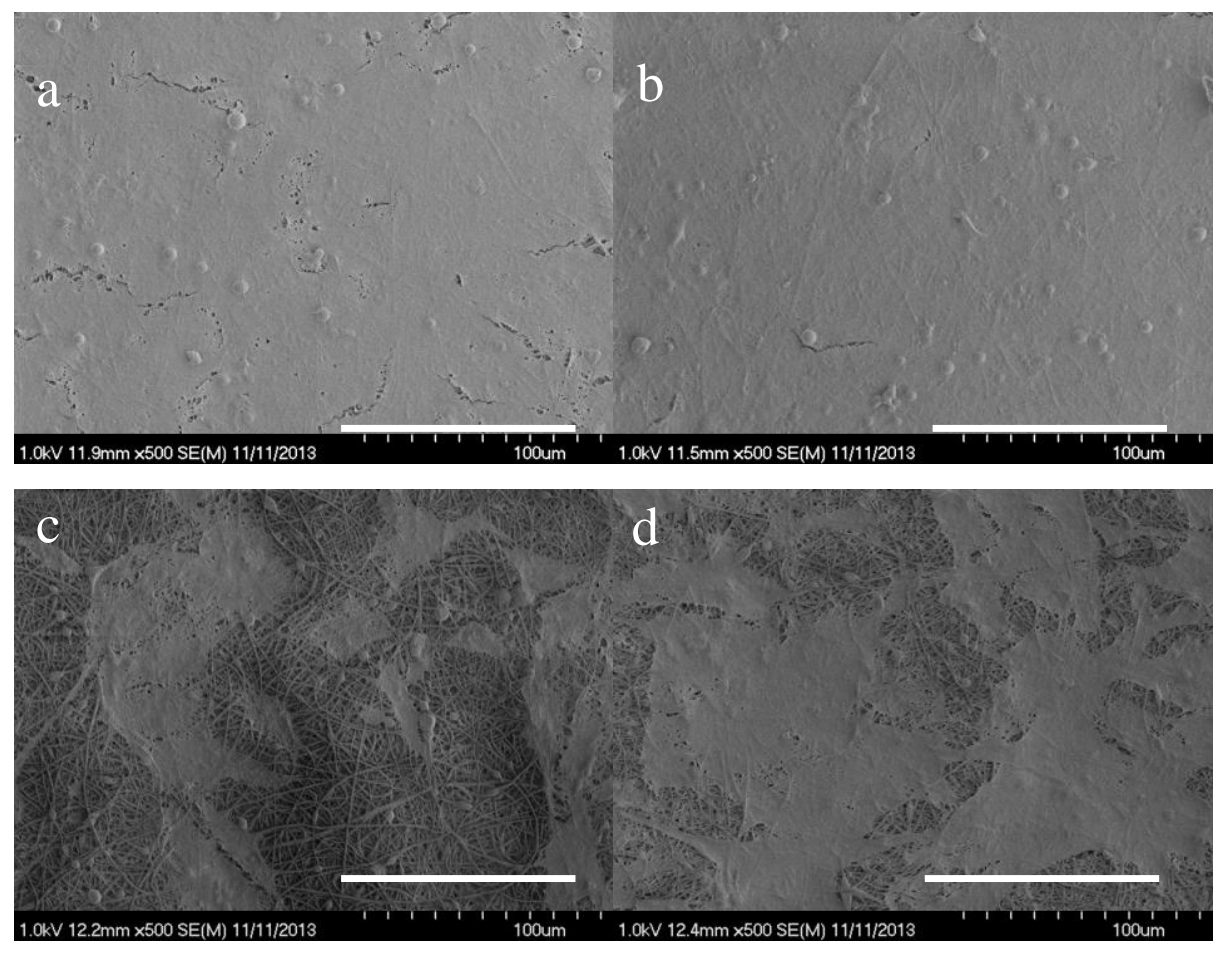
Figure 10 SEM micrographs of bare (a,c) and L-PPE:N-coated (b,d) electrospun nanofiber (ePET) mats: a,b) under static conditions; c,d) under shear (scale bar: $100 \mu \mathrm{m}$ )

\section{General Discussion and Conclusion}

The primary requirements for a synthetic functional vascular graft (VG) are biocompatibility, bioactivity, and favorable mechanical properties [13]. The current generation of VGs is mainly limited by inadequate mechanical properties that lead to mismatch and intimal hyperplasia, and by lacking spontaneous endothelialization of the lumen surface. Pre-endothelialization of the lumen has shown promise as a strategy to improve small-diameter VGs, but it is still handicapped by poor adhesion and retention of endothelial cells (ECs) [57, 58].

In the present study two well-documented techniques, electrospinning and plasma polymerization (PP) of an amine-rich coating, were combined to address the issues mentioned above, that is, to create an effective scaffold for subsequent EC-seeding. Electrospun 3D PET mats (ePET) with random fiber orientation were prepared, PET being chosen because it is stable, cost-effective and cytocompatible, with tunable properties and because several PET-based vascular implants have already received FDA-approval [59]. Electrospun PET exhibits relatively low stiffness and favorable strength that can be of interest for VG applications, its tensile properties being comparable to those of natural arteries $[15,27,33,60]$.

Although further investigation is warranted, present results reveal no deleterious effect of L-PPE:N coating on the properties of ePET mats, thanks to the mild plasma conditions employed (low power, $10 \mathrm{~W}$; pressure, $600 \mathrm{mTorr}$; and temperature, $300 \mathrm{~K}$ ).

The morphology of our electrospun PET 3D nanofibre network proved suitable for forming a nearconfluent endothelial cell (EC) monolayer lining, see Figure 8b and 10. Indeed, the fabrication conditions yielded high porosity and small pore size (Figure 1) that enable exchange of nutrients and gas molecules, while restricting EC growth to the topmost (eventual lumen) surface [61]. This is greatly advantageous compared with presently used ePTFE and woven PET grafts, where cells penetrate and do not readily form such a complete EC monolayer (see Figure 7 and 8d).

Cell adhesion, -growth and -retention under flow-induced shear stress were shown to be limited on bare ePET mats, but L-PPE:N coating helped overcome this limitation to a large extent. Earlier 
work in these laboratories had already proven L-PPE:N to be highly effective, reproducible and sufficiently stable over time for cell culture applications [40, 62, 63]. Here, the greatly-enhanced cell density on L-PPE:N-coated scaffolds compared with bare samples (see Figure 6) confirmed the coating as an excellent pre-treatment for the requisite HUVEC response; this was not surprising in view of similar observations we reported for HUVEC, but also for vascular smooth muscle cells (VSMCs), fibroblasts and mesenchymal stem cells (MSC) [39, 63-65]. It also agrees with other groups' findings that functionalized PP coatings can enhance cell adhesion, growth and proliferation on diverse electrospun substrates $[36,66]$. PP with appropriate chemical functionalities, primary amine $\left(-\mathrm{NH}_{2}\right)$ groups in the case of L-PPE:N, rapidly attract and bind proteins in bio-fluids or culture media; integrin receptors on cells' outer membrane surfaces, in turn, "recognize" and bind to certain of these proteins. In aqueous solution at physiological $\mathrm{pH}$ values, the protonated amine group possesses a localised positive charge which helps attract the negatively-charged biomolecules (proteins) and cells [67]. Because L-PPE:N promotes the attachment of many different cell types, pre-seeding with endothelial cells should precede in-vivo implantation. On the other hand, it can also serve to create complete tissue-engineered vascular grafts (TEVG).

There have recently been several reported efforts to create TEVGs based on electrospining, for example bilayered scaffolds or hybrid scaffolds made by combining natural and synthetic polymer mats. Let us mention bilayered scaffolds of PCL-collagen blend [68], elastin, type I collagen and poly (D,L-lactide-co-glycolide) (PLGA) [69], multi-layered type I collagen, gelatin, segmented polyurethane and poly(ethylene oxide) [70], and collagen/ chitosan/thermoplastic polyurethane nanofibrous scaffolds [71]. Although collagen is known to increase cell adhesion, its possible immunogenic effects, rapid degradation, and cost of synthetic collagen constitute important challenges [72]. L-PPE:N can be deposited on any type of surface and could be used with other electrospun material, resorbable or not. As a logical future step, the combination presented here (electrospinning + PP) will be used to add a more porous electrospun outer layer, either of PET or of a biodegradable polymer, to favor growth of a thick VSMC layer and obtain a complete scaffold for TEVG.

In conclusion, the combination of electrospinning and primary-amine rich plasma polymer coating proposed in this research can provide an adequate scaffold for the luminal side of small-diameter vascular prostheses; more precisely, it enables finely-controlled structural, mechanical and surface 
properties that are required for confluent, flow-stable pre-endothelialization of VGs or TEVG. These improvements may help overcome the clinical complications encountered when using current generations of off-the-shelf VG prostheses.

\section{Acknowledgments}

This research is being supported by grants from the Natural Sciences and Engineering Research Council of Canada (NSERC) and the Canadian Institutes of Health Research (CIHR) (CPG 87497). One of us (H.S.) gratefully acknowledges the Fonds de recherche du Québec-Nature et technologies (FQRNT) for the award of its Merit Scholarship. The authors also thank C. Cerclé, N. MacDonald, S. Poulin, J. Lefebvre, Y. Leblanc (Ecole Polytechnique), K. Hamelin, B. La Colla (CHUM), as well as S. St-Amour and S. Sauriol (FPInnovations) for technical support during experiments. 
[1] T.A. Gaziano, Cardiovascular disease in the developing world and its cost-effective management, Circulation 112(23) (2005) 3547-3553.

[2] R.Y. Kannan, H.J. Salacinski, P.E. Butler, G. Hamilton, A.M. Seifalian, Current status of prosthetic bypass grafts: A review, J. Biomed. Mater. Res. Part B 74B(1) (2005) 570-581.

[3] S. Sarkar, T. Schmitz-Rixen, G. Hamilton, A.M. Seifalian, Achieving the ideal properties for vascular bypass grafts using a tissue engineered approach: a review, Med. Biol. Eng. Comput. 45(4) (2007) 327-336.

[4] C.Y. Xu, R. Inai, M. Kotaki, S. Ramakrishna, Electrospun nanofiber fabrication as synthetic extracellular matrix and its potential for vascular tissue engineering, Tissue Eng. 10(7-8) (2004) 1160-1168.

[5] S. Agarwal, J.H. Wendorff, A. Greiner, Use of electrospinning technique for biomedical applications, Polymer 49(26) (2008) 5603-5621.

[6] W. He, Z.W. Ma, W.E. Teo, Y.X. Dong, P.A. Robless, T.C. Lim, S. Ramakrishna, Tubular nanofiber scaffolds for tissue engineered small-diameter vascular grafts, J. Biomed. Mater. Res. Part A 90A(1) (2009) 205-216.

[7] C. Grasl, H. Bergmeister, M. Stoiber, H. Schima, G. Weigel, Electrospun polyurethane vascular grafts: In vitro mechanical behavior and endothelial adhesion molecule expression, Journal of Biomedical Materials Research Part A 93A(2) (2010) 716-723.

[8] M. Zhang, K. Wang, Z.X. Wang, B. Xing, Q. Zhao, D.L. Kong, Small-diameter tissue engineered vascular graft made of electrospun PCL/lecithin blend, J. Mater. Sci.-Mater. Med. 23(11) (2012) 2639-2648.

[9] N. Detta, C. Errico, D. Dinucci, D. Puppi, D.A. Clarke, G.C. Reilly, F. Chiellini, Novel electrospun polyurethane/gelatin composite meshes for vascular grafts, J. Mater. Sci.-Mater. Med. 21(5) (2010) 1761-1769.

[10] A. Andukuri, M. Kushwaha, A. Tambralli, J.M. Anderson, D.R. Dean, J.L. Berry, Y.D. Sohn, Y.S. Yoon, B.C. Brott, H.W. Jun, A hybrid biomimetic nanomatrix composed of electrospun polycaprolactone and bioactive peptide amphiphiles for cardiovascular implants, Acta Biomater. 7(1) (2011) 225-233.

[11] X. Zhang, V. Thomas, Y.K. Vohra, Two ply tubular scaffolds comprised of proteins/poliglecaprone/polycaprolactone fibers, J. Mater. Sci.-Mater. Med. 21(2) (2010) 541-549.

[12] S.G. Wise, M.J. Byrom, A. Waterhouse, P.G. Bannon, M.K.C. Ng, A.S. Weiss, A multilayered synthetic human elastin/polycaprolactone hybrid vascular graft with tailored mechanical properties, Acta Biomater. 7(1) (2011) 295-303.

[13] A. Hasan, A. Memic, N. Annabi, M. Hossain, A. Paul, M.R. Dokmeci, F. Dehghani, A. Khademhosseini, Electrospun scaffolds for tissue engineering of vascular grafts, Acta Biomater. 10(1) (2014) 11-25.

[14] D. Shum-Tim, U. Stock, J. Hrkach, T. Shinoka, J. Lien, M.A. Moses, A. Stamp, G. Taylor, A.M. Moran, W. Landis, R. Langer, J.P. Vacanti, J.E. Mayer, Tissue engineering of autologous aorta using a new biodegradable polymer, Ann. Thorac. Surg. 68(6) (1999) 2298-2304. 
[15] A. Hadjizadeh, A. Ajji, M.N. Bureau, Nano/micro electro-spun polyethylene terephthalate fibrous mat preparation and characterization, J. Mech. Behav. Biomed. Mater. 4(3) (2011) 340351.

[16] H. Cardinal, M.J. Hebert, M.A. Raymond, F. Madore, Uremic Serum Down-Regulates Cell Cycle and Cholesterol Efflux Genes in Human Coronary Artery Endothelial Cells, Journal of the American Society of Nephrology (in press) abstract (2005).

[17] Z.W. Ma, M. Kotaki, T. Yong, W. He, S. Ramakrishna, Surface engineering of electrospun polyethylene terephthalate (PET) nanofibers towards development of a new material for blood vessel engineering, Biomaterials 26(15) (2005) 2527-2536.

[18] M. Chun, C.S. Nabzdyk, J.D. Glaser, S. Pathan, M. Phaneuf, J.-O. You, L. Pradhan-Nabzdyk, F.W. LoGerfo, Composite Electrospun Polyethylene Terephthalate: A Method Towards Improving Graft Patency, Journal of Vascular Surgery 56(5) (2012) 1482.

[19] B. Veleirinho, M.F. Rei, J.A. Lopes-da-Silva, Solvent and concentration effects on the properties of electrospun poly(ethylene terephthalate) nanofiber mats, J. Polym. Sci. Pt. B-Polym. Phys. 46(5) (2008) 460-471.

[20] M.C. Burrows, V.M. Zamarion, F.B. Filippin-Monteiro, D.C. Schuck, H.E. Toma, A. Campa, C.R.S. Garcia, L.H. Catalani, Hybrid Scaffolds Built From PET and Collagen as a Model For Vascular Graft Architecture, Macromol. Biosci. 12(12) (2012) 1660-1670.

[21] A. Gigout, J.C. Ruiz, M.R. Wertheimer, M. Jolicoeur, S. Lerouge, Nitrogen-Rich PlasmaPolymerized Coatings on PET and PTFE Surfaces Improve Endothelial Cell Attachment and Resistance to Shear Flow, Macromol. Biosci. 11(8) (2011) 1110-1119.

[22] R.S. Benson, Use of radiation in biomaterials science, Nucl. Instrum. Methods Phys. Res. Sect. B-Beam Interact. Mater. Atoms 191 (2002) 752-757.

[23] F. Poncinepaillard, B. Chevet, J.C. Brosse, Modification of isotactic polypropylene by a coldplasma or an electron-beam and grafting of the acrylic-acid onto these activated polymers, Journal of Applied Polymer Science 53(10) (1994) 1291-1306.

[24] F. Abbasi, H. Mirzadeh, A.A. Katbab, Bulk and surface modification of silicone rubber for biomedical applications, Polym. Int. 51(10) (2002) 882-888.

[25] Z.W. Ma, Z.W. Mao, C.Y. Gao, Surface modification and property analysis of biomedical polymers used for tissue engineering, Colloid Surf. B-Biointerfaces 60(2) (2007) 137-157.

[26] P.K. Chu, J.Y. Chen, L.P. Wang, N. Huang, Plasma-surface modification of biomaterials, Mater. Sci. Eng. R-Rep. 36(5-6) (2002) 143-206.

[27] A. Hadjizadeh, A. Ajji, M.N. Bureau, Preparation and characterization of $\mathrm{NaOH}$ treated micro-fibrous polyethylene terephthalate nonwovens for biomedical application, J. Mech. Behav. Biomed. Mater. 3(8) (2010) 574-583.

[28] H. Savoji, D. Rana, T. Matsuura, S. Tabe, C. Feng, Development of plasma and/or chemically induced graft co-polymerized electrospun poly (vinylidene fluoride) membranes for solute separation, Separation and Purification Technology 108 (2013) 196-204. 
[29] Z.Y. Ma, Y.P. Guan, X.Q. Liu, H.Z. Liu, Synthesis of magnetic chelator for high-capacity immobilized metal affinity adsorption of protein by cerium initiated graft polymerization, Langmuir 21(15) (2005) 6987-6994.

[30] J. Marchandbrynaert, M. Deldime, I. Dupont, J.L. Dewez, Y.J. Schneider, Surface functionalization of poly(ethylene-terephthalate) film and membrane by controlled wet chemistry - chemical characterization of carboxylated surfaces, J. Colloid Interface Sci. 173(1) (1995) 236244.

[31] C. Salvagnini, A. Roback, M. Momtaz, V. Pourcelle, J. Marchand-Brynaert, Surface functionalization of a poly(butylene terephthalate) (PBT) melt-blown filtration membrane by wet chemistry and photo-grafting, J. Biomater. Sci.-Polym. Ed. 18(12) (2007) 1491-1516.

[32] M. Voue, E. Goormaghtigh, F. Homble, J. Marchand-Brynaert, J. Conti, S. Devouge, J. De Coninck, Biochemical interaction analysis on ATR devices: A wet chemistry approach for surface functionalization, Langmuir 23(2) (2007) 949-955.

[33] A. Hadjizadeh, A. Ajji, M. Jolicoeur, B. Liberelle, G. De Crescenzo, Effects of Electrospun Nanostructure versus Microstructure on Human Aortic Endothelial Cell Behavior, Journal of Biomedical Nanotechnology 9(7) (2013) 1195-1209.

[34] J.G.A. Terlingen, A.S. Hoffman, J. Feijen, Effect of glow-discharge treatment of poly(acrylic acid) pre-adsorbed onto poly(ethylene), Journal of Applied Polymer Science 50(9) (1993) 15291539 .

[35] F. Truica-Marasescu, M.R. Wertheimer, Nitrogen-rich plasma-polymer films for biomedical applications, Plasma Process. Polym. 5(1) (2008) 44-57.

[36] K.S. Siow, L. Britcher, S. Kumar, H.J. Griesser, Plasma methods for the generation of chemically reactive surfaces for biomolecule immobilization and cell colonization-a review, Plasma Process. Polym. 3(6-7) (2006) 392-418.

[37] A. Guex, F. Kocher, G. Fortunato, E. Körner, D. Hegemann, T. Carrel, H. Tevaearai, M. Giraud, Fine-tuning of substrate architecture and surface chemistry promotes muscle tissue development, Acta Biomater. 8(4) (2012) 1481-1489.

[38] F. Truica-Marasescu, M.R. Wertheimer, Nitrogen-Rich Plasma-Polymer Films for Biomedical Applications, Plasma Process. Polym. 5(1) (2008) 44-57.

[39] A. Gigout, J.C. Ruiz, M.R. Wertheimer, M. Jolicoeur, S. Lerouge, Nitrogen-Rich PlasmaPolymerized Coatings on PET and PTFE Surfaces Improve Endothelial Cell Attachment and Resistance to Shear Flow, Macromol. Biosci. 11(8) (2011) 1110-1119.

[40] J.C. Ruiz, A. St-Georges-Robillard, C. Thérésy, S. Lerouge, M.R. Wertheimer, Fabrication and Characterisation of Amine-Rich Organic Thin Films: Focus on Stability, Plasma Process. Polym. 7(9-10) (2010) 737-753.

[41] A. St-Georges-Robillard, J.C. Ruiz, A. Petit, H.T. Wang, F. Mwale, B. Elkin, C. Oehr, S. Lerouge, M.R. Wertheimer, Adhesion of U-937 Monocytes on Different Amine-functionalised Polymer Surfaces, Plasma Process. Polym. 9(3) (2012) 243-252.

[42] S.T. Ho, D.W. Hutmacher, A comparison of micro CT with other techniques used in the characterization of scaffolds, Biomaterials 27(8) (2006) 1362-1376. 
[43] P. Favia, M.V. Stendardo, R. d'Agostino, Selective grafting of amine groups on polyethylene by means of NH3- H2 RF glow discharges, Plasmas and Polymers 1(2) (1996) 91-112.

[44] A.M. Malek, S.L. Alper, S. Izumo, Hemodynamic shear stress and its role in atherosclerosis, Jama 282(21) (1999) 2035-2042.

[45] N.G. dela Paz, P.A. D'Amore, Arterial versus venous endothelial cells, Cell and Tissue Research 335(1) (2009) 5-16.

[46] H. Salacinski, A. Tiwari, G. Hamilton, A. Seifalian, Cellular engineering of vascular bypass grafts: role of chemical coatings for enhancing endothelial cell attachment, Medical and Biological Engineering and Computing 39(6) (2001) 609-618.

[47] C. Wang, L. Cen, S. Yin, Q. Liu, W. Liu, Y. Cao, L. Cui, A small diameter elastic blood vessel wall prepared under pulsatile conditions from polyglycolic acid mesh and smooth muscle cells differentiated from adipose-derived stem cells, Biomaterials 31(4) (2010) 621-630.

[48] S. Sell, M.J. McClure, C.P. Barnes, D.C. Knapp, B.H. Walpoth, D.G. Simpson, G.L. Bowlin, Electrospun polydioxanone-elastin blends: potential for bioresorbable vascular grafts, Biomedical Materials 1(2) (2006) 72.

[49] W. He, Z. Ma, T. Yong, W.E. Teo, S. Ramakrishna, Fabrication of collagen-coated biodegradable polymer nanofiber mesh and its potential for endothelial cells growth, Biomaterials 26(36) (2005) 7606-7615.

[50] K. Schröder, A. Meyer-Plath, D. Keller, W. Besch, G. Babucke, A. Ohl, Plasma-Induced Surface Functionalization of Polymeric Biomaterials in Ammonia Plasma, Contributions to Plasma Physics 41(6) (2001) 562-572.

[51] A. Meyer-Plath, K. Schröder, B. Finke, A. Ohl, Current trends in biomaterial surface functionalization-nitrogen-containing plasma assisted processes with enhanced selectivity, Vacuum 71(3) (2003) 391-406.

[52] R. Wyrwa, B. Finke, H. Rebl, N. Mischner, M. Quaas, J. Schaefer, C. Bergemann, J.B. Nebe, K. Schroeder, K.D. Weltmann, Design of Plasma Surface-Activated, Electrospun Polylactide NonWovens with Improved Cell Acceptance, Advanced Engineering Materials 13(5) (2011) B165B171.

[53] Z. Ma, M. Kotaki, T. Yong, W. He, S. Ramakrishna, Surface engineering of electrospun polyethylene terephthalate (PET) nanofibers towards development of a new material for blood vessel engineering, Biomaterials 26(15) (2005) 2527-2536.

[54] W. He, Z. Ma, W.E. Teo, Y.X. Dong, P.A. Robless, T.C. Lim, S. Ramakrishna, Tubular nanofiber scaffolds for tissue engineered small-diameter vascular grafts, J. Biomed. Mater. Res. Part A 90(1) (2009) 205-216.

[55] B.C. Heng, P.P. Bezerra, P.R. Preiser, S. Alex Law, Y. Xia, F. Boey, S.S. Venkatraman, Effect of cell-seeding density on the proliferation and gene expression profile of human umbilical vein endothelial cells within ex vivo culture, Cytotherapy 13(5) (2011) 606-617.

[56] C. Charbonneau, J.C. Ruiz, P. Lequoy, M.J. Hébert, G. De Crescenzo, M.R. Wertheimer, S. Lerouge, Chondroitin Sulfate and Epidermal Growth Factor Immobilization after Plasma Polymerization: A Versatile Anti-Apoptotic Coating to Promote Healing Around Stent Grafts, Macromol. Biosci. 12(6) (2012) 812-821. 
[57] E. Vinard, G. Lesèche, B. Andreassian, D. Costagliola, In vitro endothelialization of PTFE vascular grafts: A comparison of various substrates, cell densities, and incubation times, Annals of Vascular Surgery 13(2) (1999) 141-150.

[58] S. Wang, X.M. Mo, B.J. Jiang, C.J. Gao, H.S. Wang, Y.G. Zhuang, L.J. Qiu, Fabrication of small-diameter vascular scaffolds by heparin-bonded P (LLA-CL) composite nanofibers to improve graft patency, International Journal of Nanomedicine 8 (2013) 2131-2139.

[59] C. Bouten, P. Dankers, A. Driessen-Mol, S. Pedron, A. Brizard, F. Baaijens, Substrates for cardiovascular tissue engineering, Advanced Drug Delivery Reviews 63(4) (2011) 221-241.

[60] M. Moreno, A. Ajji, D. Mohebbi-Kalhori, M. Rukhlova, A. Hadjizadeh, M. Bureau, Development of a compliant and cytocompatible micro-fibrous polyethylene terephthalate vascular scaffold, Journal of Biomedical Materials Research Part B: Applied Biomaterials 97(2) (2011) 201-214.

[61] S. Ramakrishna, K. Fujihara, W.-E. Teo, T. Yong, Z. Ma, R. Ramaseshan, Electrospun nanofibers: solving global issues, Materials Today 9(3) (2006) 40-50.

[62] J.-C. Ruiz, P.-L. Girard-Lauriault, F. Truica-Marasescu, M.R. Wertheimer, Plasma-and vacuum-ultraviolet (VUV) photo-polymerisation of $\mathrm{N}$-and O-rich thin films, Radiation Physics and Chemistry 79(3) (2010) 310-314.

[63] P.L. Girard-Lauriault, F. Truica-Marasescu, A. Petit, H.T. Wang, P. Desjardins, J. Antoniou, F. Mwale, M.R. Wertheimer, Adhesion of Human U937 Monocytes to Nitrogen-Rich Organic Thin Films: Novel Insights into the Mechanism of Cellular Adhesion, Macromol. Biosci. 9(9) (2009) 911-921.

[64] C. Charbonneau, B. Liberelle, M.-J. Hébert, G. De Crescenzo, S. Lerouge, Stimulation of cell growth and resistance to apoptosis in vascular smooth muscle cells on a chondroitin sulfate/epidermal growth factor coating, Biomaterials 32(6) (2011) 1591-1600.

[65] S. Lerouge, A. Major, P.-L. Girault-Lauriault, M.-A. Raymond, P. Laplante, G. Soulez, F. Mwale, M.R. Wertheimer, M.-J. Hébert, Nitrogen-rich coatings for promoting healing around stent-grafts after endovascular aneurysm repair, Biomaterials 28(6) (2007) 1209-1217.

[66] W. He, T. Yong, Z.W. Ma, R. Inai, W.E. Teo, S. Ramakrishna, Biodegradable polymer nanofiber mesh to maintain functions of endothelial cells, Tissue Eng. 12(9) (2006) 2457-2466.

[67] M.R. Wertheimer, A. St-Georges-Robillard, S. Lerouge, F. Mwale, B. Elkin, C. Oehr, W. Wirges, R. Gerhard, Amine-rich organic thin films for cell culture: possible electrostatic effects in cell-surface interactions, Japanese Journal of Applied Physics 51(11S) (2012) 11PJ04.

[68] Y.M. Ju, J. San Choi, A. Atala, J.J. Yoo, S.J. Lee, Bilayered scaffold for engineering cellularized blood vessels, Biomaterials 31(15) (2010) 4313-4321.

[69] J. Stitzel, J. Liu, S.J. Lee, M. Komura, J. Berry, S. Soker, G. Lim, M. Van Dyke, R. Czerw, J.J. Yoo, Controlled fabrication of a biological vascular substitute, Biomaterials 27(7) (2006) 1088-1094.

[70] C.E. Ayres, B.S. Jha, H. Meredith, J.R. Bowman, G.L. Bowlin, S.C. Henderson, D.G. Simpson, Measuring fiber alignment in electrospun scaffolds: a user's guide to the 2D fast Fourier transform approach, Journal of Biomaterials Science, Polymer Edition 19(5) (2008) 603-621. 
[71] F. Chen, Y. Su, X. Mo, C. He, H. Wang, Y. Ikada, Biocompatibility, alignment degree and mechanical properties of an electrospun chitosan-P (LLA-CL) fibrous scaffold, Journal of Biomaterials Science, Polymer Edition 20(14) (2009) 2117-2128.

[72] A. Lynn, I. Yannas, W. Bonfield, Antigenicity and immunogenicity of collagen, Journal of Biomedical Materials Research Part B: Applied Biomaterials 71(2) (2004) 343-354. 